\title{
Social Interdependence and the Promotion of Cooperative Learning
}

\author{
Fabrizio Butera and Céline Buchs
}

\section{Contents}

Introduction 111

Social Interdependence

Psychological Processes in Social Interdependence

Cooperation 114

Cooperative Learning Methods . 116

Positive Interdependence and Social

Comparison

Inspiring and Threatening Partners

Competence Threat

The Promotion of Cooperative Methods

Recommended Reading 120

Guiding Answers to Questions in the Chapter ...

References

F. Butera $(\bowtie)$

University of Lausanne, Lausanne, Switzerland

e-mail: fabrizio.butera@unil.ch

C. Buchs

University of Geneva, Geneva, Switzerland

\section{Introduction}

We have all observed, at school, in professional settings and in sports, that some groups work in harmony, with members coordinating their actions and helping each other. Other groups, however, experience a great deal of antagonism, with members favoring their own interest and acting against each other. What explains such differences? How can the functioning of a group be predicted and possibly oriented? At an individual level of analysis, group members may have different-sometimes compatible, sometimes conflicting-personal orientations, and be more pro-social or pro-self, thereby favoring joint or self-serving outcomes (De Cremer \& Van Lange, 2001). Group members may also hold mixed motives in a given situation, as a function of their focus on the task at hand as well as the social relations in the group (De Dreu, Nijstad, \& van Knippenberg, 2008). Classmates, for instance, may be motivated to discover the correct solution to a problem in a physics lab class, and at the same time motivated to show their own competence to the teacher.

An individual level of analysis requires a strong reliance on group composition to predict how groups will behave (Moreland \& Levine, 1992). Groups, however, possess particular properties that are likely to influence group members' behavior over and beyond their 
personal orientation. One such propertyimposed by the environment or inherited by the group's history-is goal structure that is the set of a group's rules, norms, or practices that specify and influence the type of interdependence among individual goals (Johnson \& Johnson, 2005). Social interdependence theory posits that interdependence may be positive and lead to interactions that facilitate the attainment of all group members' goals, or negative and lead to interactions that favor one's goal attainment by hindering the goal attainment of other group members (Deutsch, 1949). For example, in the famous Robbers Cave study (Sherif, 1958), children in a summer camp discovered that the truck with the day's food was stuck, and could only be rescued if all the children pulled it in synchrony. The situation created a common goal (retrieve the food), superordinate as compared to individual goals, and required coordinated interaction of all children to reach that goal (for a discussion of the role of common goals in intergroup contact, see Christ \& Kauff, Chap. 10, this volume). In the same study, Sherif observed that other activities, such as tournaments that allowed to win a desired prize, required teams to fight with the understanding that success of one team required hindering the other team.

This chapter will present the tenets of social interdependence theory and the work that this theory has generated over the past 70 years. Then, we will show how this theory has shaped research on cooperative learning, and in particular research on how pupils and students share or not the materials and resources necessary for learning. Finally, we will illustrate how difficult it is to promote positive interdependence and present an intervention study designed to help in this endeavor.

\section{Definition Box}

Interaction: Individuals' coordinated actions that have consequences for other individuals' cognitions, affects, and behaviors.
Goal structure: The structure consisting of a group's set of rules, norms, or practices of a group that determines how each group member's opportunities for goal achievement depend on those of other group members, i.e., their social interdependence.

\section{Social Interdependence}

Social interdependence theory was born as a theory of cooperation and competition (Deutsch, 1949). Over the years, it has been extremely successful because, instead of describing cooperation and competition as separate phenomena, it allowed to understand their interplay by grounding their emergence in a common mechanism: social interdependence. Social interdependence is the mechanism whereby the outcomes of individuals in a group are affected by the actions of the other group members (see also Johnson \& Johnson, 1989). Let us imagine two pupils in a classroom, where they are likely to interact and be interdependent. If the teacher has given the two pupils a common assignment, then they find themselves in a position of positive social interdependence, as the actions of each of them will jointly contribute to the quality of the assignment. This example illustrates how the positive interdependence introduced by the teacher can contribute to cooperative behaviors and promotive interactions, i.e., working toward the achievement of a common goal. If, on the contrary, the teacher has asked the pupils to write an essay and told them that the best one will be published in the school's newsletter, the two pupils find themselves in a position of negative social interdependence, as the actions of each of them will hamper the goal of the other (be the one whose essay is published in the school's newsletter). This example illustrates how the negative interdependence introduced by the teacher might facilitate competitive behaviors and 
oppositional interactions, i.e., working toward the achievement of one's own goal to the detriment of the other's (Deutsch, 1949).

It is worth noting at this point that social interdependence is a structural property of the environment, namely, a set of constraints that affect people's behaviors. These constraints can be material: The members of a rowing team are necessarily positively interdependent, as none of them can fulfill the goal of winning without the others (e.g., Dyson, 2001), and the students sitting an entrance exam with numerus clausus for a prestigious curriculum are necessarily negatively interdependent, as the success of one reduces the chances of success of the others (e.g., Kaufman, 1994; Sommet, Pulfrey, \& Butera, 2013). The constraints can also be symbolic, for instance, the collectivistic and individualistic culture (Triandis, 1993), or the self-transcendence and self-enhancement values (Schwartz et al., 2012) of a given society. Whatever be the nature of social interdependence, this structural property of the environment exerts a strong influence on people's behaviors and perceptions, resulting either in actual cooperation or competition-characterized by promotive or oppositional interactions (e.g., Johnson \& Johnson, 1974)—or in cooperative or competitive climates-characterized by perceived promotive or oppositional relationships (e.g., Elliot, Jury, \& Murayama, 2018).

Importantly, the reliance on the concept of social interdependence allows differentiating cooperation and competition from other phenomena that may also be present in social settings. Going back to our two pupils, they may find themselves in a position of independence, if the teacher has asked them to work alone, each with their own materials, and evaluates their work based on predefined criteria. In this case, the actions of one do not affect the outcomes of the other. They may also find themselves in a position in which one is dependent on the other, if the teacher has asked one pupil to help a schoolmate, as in tutoring. In this case, the actions of one

\section{Definition Box}

Social interdependence: The actions and outcomes of individuals are affected by each other's actions.

Cooperation: Positive social interdependence. The actions of each individual contribute to some common goal; individual goals are positively associated. The success of one supports the likelihood of success of others.

Competition: Negative social interdependence. The actions of one individual hamper the goal of the other; individual goals are negatively associated. The success of one reduces the likelihood of success of others.

affect the outcomes of the other, but not vice versa (Johnson \& Johnson, 2005).

\section{Psychological Processes in Social Interdependence}

How does social interdependence, either positive or negative, result in the expected outcomes, namely, the emergence of cooperation with its promotive behaviors, or competition with its oppositional behaviors, respectively? Three important processes appear to be at work in social interdependence (Deutsch, 1962). First, substitutability refers to the extent to which a group member's actions can substitute for the actions of another group member. Let us imagine that our two pupils are working together on a joint assignment, say a report on the geography of India: If pupil number one completes a section of the assignment for pupil number two, the latter will be satisfied and will not feel the need to complete that section by him/herself, because in cooperation the partners' actions are substitut- 
able. If the two pupils have well understood what positive interdependence is about, pupil number two will reciprocate in a future task. This, of course, provided that actions are effective, that is functional in reaching the goal (in this example, to write a good report): If one partner's actions are not effective, then the other will have to expend more effort to compensate, thereby thwarting cooperation's important role of evenly distributing the effort. However, it is clear from our example that effective actions are not substitutable in the case of competition: If pupil number one completes a section of the assignment more quickly or instead of pupil number two, thereby signaling greater competence to the teacher, pupil number two will not be satisfied and will feel the need to exert extra effort to bridge the gap.

Second, social interdependence involves cathexis, a substantial affective investment in the actions and persons involved in an interaction. In cooperation, positive cathexis is attached to effective actions, and negative cathexis is attached to ineffective actions of the partner. Indeed, effective actions are likely to result in reaching the group's common goal, whereas ineffective actions (or "bungling" as Deutsch calls them) are likely to hinder such a goal. In competition, however, negative cathexis is attached to effective actions, and positive cathexis is attached to ineffective actions of the competitor. Indeed, effective actions of the competitor are likely to result in hindering one's individual goal, whereas ineffective actions are likely to favor it. For instance, a study showed that under negative interdependence, participants actively engaged in claiming one's self-superiority in terms of competence as compared to a partner who might have had a good point in a problemsolving task (Butera \& Mugny, 1995).

Third, inducibility refers to the reciprocal influence that partners exert on each other. This process is particularly important in positive social interdependence. Inducibility leads the partners to engage in effective actions that may be useful for the common goal and refrain from actions that may interfere with such a goal. Under negative social interdependence, competitors will try to resist each other's influence in order to avoid losing some competitive advantage. For example, experts working under negative interdependence have been shown to resist the other's influence, their expertise notwithstanding (Butera \& Mugny, 2001; Quiamzade \& Mugny, 2009). In sum, social

\section{Box 8.1 Question for Elaboration}

Imagine a cohesive and cooperative volleyball team. Give an example describing how substitutability, positive cathexis, and inducibility intervene during a match.

interdependence creates a dense affective and behavioral network within a group, in which group members develop meaningful representations, affects, and actions in relation to others, either positive or negative depending on whether group members are tied by cooperation or competition.

\section{Cooperation}

Social interdependence theory has been instrumental in the development of a systematic theory of cooperation and competition. Moreover, it has led to the development of a long-lasting and productive area of research that has investigated the mechanisms that make cooperation more effective-in terms of effort to achieve positive relationships, psychological adjustment, and social competence - than competition or individual work (Johnson \& Johnson, 1989). This area of research has also uncovered the mechanisms that, as a result, lead cooperation to Promote higher productivity and achievement, better interpersonal relationships, psychological health, and self-esteem (Johnson \& Johnson, 2015). In particular, the work by Johnson and Johnson (see 2009 for a review) has uncovered five principles that contribute to the effectiveness of cooperation (see Fig. 8.1).

1. Positive interdependence. As mentioned earlier, it is crucial for group members to pursue common goals or to consider that individual 
Fig. 8.1 Five principles that contribute to the effectiveness of cooperation. Why are responsibility and accountability important to cooperation? What do they add to positive goal interdependence?

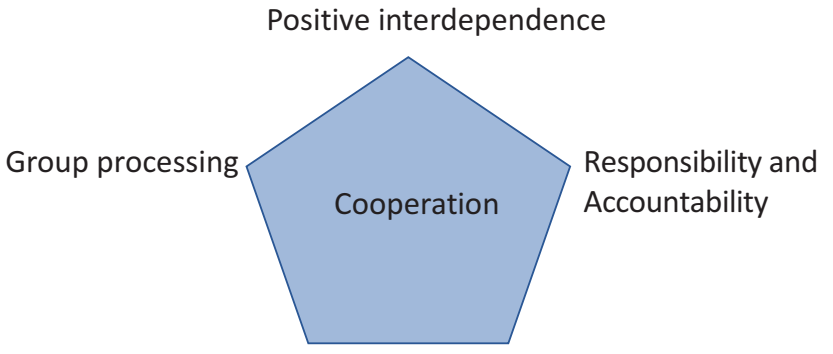

Social skills
Promotive interactions

\section{Box 8.2 Zooming In: Sources of Interdependence}

When we mentioned interdependence, we referred to goal interdependence, as this was part of Deutsch's original formulation and is necessary for cooperative learning. It is important, however to consider other sources of interdependence, as they may all be used in a group to create effective cooperation. Johnson and Johnson $(1989,2009)$ distinguish three categories of interdependence: outcome, means, and boundary interdependence. Outcome interdependence refers to desired states and includes goal interdependence as well as reward interdependence: Indeed, a group of pupils may be interdependent because they pursue the same goal-handing in a project or ensuring that all teammates learn-but also because they expect that all the pupils who worked on the same project will receive the same rewarda common grade or the same bonus points. Group members may also be interdependent because they need to share the means involved in their work: They may have to share complementary resources (like in the jigsaw classroom, cf., Aronson \& Patnoe, 1997), take turns in complementary roles, or each be responsible for a different task in the same assignment. Finally, boundaries specify who is interdependent with whom, typically by specifying who is in a group (interdependence) and who is in another group (independence-unless the other group is an ally or a rival). goals are positively linked in order to work cooperatively (see also Sherif, 1966). Beyond this theoretical statement, it was demonstrated that, indeed, positive interdependence yielded stronger positive effects on achievement than mere group membership (Hwong, Caswell, Johnson, \& Johnson, 1993) or mere interaction (Lew, Mesch, Johnson, \& Johnson, 1986).

2. Responsibility and accountability. If group members strive for the same goal, then they are responsible for one another, namely for doing their share of work and for helping the others. Even if the importance of such personal responsibility seems obvious, classic research on the phenomenon of "social loafing" has shown that people may actually work less in groups (e.g., Latané, Williams, \& Harkins, 1979). More specifically, if the contribution of single group members is difficult to assess, especially in larger groups, people tend to free ride and let the others do all the work, which results in reduced group performance (Karau \& Williams, 1993). Hence, it is important that personal responsibility be accompanied by group or individual accountability: If group or individual work is visible and easy to assess, it is also easy to assess all group members' contributions to the group

\section{Definition Box}

Social loafing: The reduced effort of people in groups, as compared to individual effort. Group members who feel unidentifiable contribute less to the group. 
goals, which increases effort and commitment of each member. It is important to note that each group member should genuinely endorse personal responsibility for supporting the team's goals, to avoid that accountability merely functions as extrinsic, controlled motivation, bound to become inactive as soon as assessment and control are no longer implemented (Ryan \& Deci, 2000).

3. Promotive interactions. Working cooperatively does not mean merely working together. Actual cooperation requires teammates to cater not only to their work but also to that of their partners. In particular, cooperative teammates trust each other and exchange needed resources (e.g., Toma \& Butera, 2009), use language to construct some common knowledge (Wegerif, Mercer, \& Dawes, 1999), decenter from one's own point of view to consider or even question the partner's point of view (Butera \& Buchs, 2005), use argumentation (Muller Mirza \& Perret-Clermont, 2009), encourage others' commitment and accept mutual influence (Johnson \& Johnson, 2015), and rely on explanations and cognitive elaboration, peer modeling, peer practice, peer assessment, and correction (Slavin, 2011).

4. Social skills. Group locomotion toward a common goal requires, as we have seen, a great deal of coordination. To facilitate such a complex endeavor, group members must be trained and acquire a set of social skills (e.g., Bennett, Rolheiser, \& Stevahn, 1991; Johnson, Johnson, \& Holubec, 1993), such as the ability to trust other group members, to communicate in a precise and unequivocal manner, and to tolerate and support other members (Johnson, 2009). Most importantly, as discussion and confrontation of points of view may result in the emergence of conflict, group members must learn how to regulate conflict in a constructive manner, that is by focusing on the task at hand and knowledge, rather than their relative status (Buchs, Butera, Mugny, \& Darnon, 2004; Johnson \& Johnson, 2007; Smith, Johnson, \& Johnson, 1981).
5. Group processing. Group performance is promoted when groups engage in group processing, that is, take the time, after task completion, to reflect upon their actions, communications, decisions, and performance (Yager, Johnson, Johnson, \& Snider, 1986). Such metacognitive processes allow groups to reconsider decisions and avoid concurrence-seeking phenomena such as social loafing, as noted earlier, and "groupthink" (Janis, 1972), the mindset of highly homogeneous groups that fail to question their decisions and decisionmaking processes (see also Esser, 1998). Group processing is also instrumental in developing group efficacy, cohesion, and social identity (Johnson \& Johnson, 2009).

These five principles have been shown to be crucial, but the list is not exhaustive. For instance, based on these elements, Topping, Buchs, Duran, and Van Keer (2017) proposed to place promotive interaction (called constructive interactions by these authors, i.e., interactions that support learning) at the heart of cooperative methods, and list several other elements that contribute to the emergence of these constructive interactions in group work.

\section{Cooperative Learning Methods}

The principles of social interdependence theory have been applied to many domains, in particular education, business, and politics. In this chapter, we focus on cooperative learning methods in educational settings, and will leave business and politics aside. Interested readers may refer to Tjosvold and Tjosvold (2015) and Johnson (2015), respectively.

The term "cooperative learning" includes a class of educational practices and pedagogical methods that aim at structuring group work by implementing the aforementioned principles of effective cooperation (e.g., Johnson, Johnson, \& Holubec, 1998). For this reason, we will use the term "cooperative methods" hereafter, for greater clarity. In fact, this class of educational practices is not homogenous and includes a great variety of 
structures and methods (Johnson, Johnson, \& Stanne, 2000; Topping et al., 2017), which may be used formally or informally, for one session or for one semester, at the classroom or at the school level (Johnson \& Johnson, 2005). This diversity notwithstanding, several authors recommend that cooperative groups be structured through positive interdependence, making sure that learners feel responsible and accountable, that they are committed to promoting each other and to communicating efficiently, in a trusting atmosphere, and in groups that reflect upon their functioning (e.g., Topping et al., 2017). In other words, positive goal interdependence represents both the structure of the cooperation (ensuring that students actually work together) and the spirit of the classroom (stimulating students to take care of both their own learning and the learning of their classmates; Topping et al., 2017; see also Abrami, 1995).

The success of cooperative learning has produced an impressive number of studies and applications, which have made it possible to quantify the effect of cooperative methods as compared to other methods, mainly competitive and individualistic. Indeed, several meta-analyses have performed an overall assessment of the effects of cooperative methods (Johnson \& Johnson, 1989; Slavin, 1983), some with a focus on university learning (Johnson \& Johnson, 2002), some with a focus on adolescents (Roseth, Johnson, \& Johnson, 2008) or elementary school pupils (Slavin, 2015). Hattie (2008) has combined several meta-analyses, and concluded that cooperative methods has an advantage in terms of performance over comparable competitive methods with an effect size of $d=0.54$ (with 7 metaanalyses and 1024 studies), as well as over individualistic methods with an effect size of

\section{Box 8.3 Zooming In: Positive Effects of Cooperative Methods}

It is important to note that, in addition to the positive effects on learning outcomes, cooperative learning yields positive effects on self-esteem and interpersonal relations (e.g., Johnson \& Johnson, 1989). The effects on self-esteem derive from the perception of being helpful and accepted typical of positive interdependence, which has also been shown to lead to better coping with stress and overall psychological and physical health (Johnson \& Johnson, 2006). The positive effects on interpersonal relations cover a wide range of behaviors, from perspective taking to listening, from greater group cohesion to lower absenteeism and fewer dropouts (Johnson \& Johnson, 2006). They also include greater acceptance of diversity (Sharan, 2010), from students of different ethnic backgrounds (Aronson \& Patnoe, 1997) and language (Buchs, Margas, Cazin, Ramirez, \& Fratianni, 2018) to students with disability (Johnson, Johnson, \& Maruyama, 1983).

$d=0.59$ (with 4 meta-analyses and 774 studies). Thus, cooperative methods appear to be effective in promoting learning, more effective than competitive and individualistic methods. Cooperative methods have been shown to promote all sorts of learning outcomes-from short-term and longterm recall of information to reasoning and creativity-in a vast array of subjects (mathematics, history, arts, etc.) and competences (computing, reading, comprehension, etc.).

\section{Positive Interdependence and Social Comparison}

The abovementioned discussion and the results from the meta-analyses reveal that cooperative methods can be instrumental in favoring learning, self-esteem, and interpersonal relations, but also that it is no magic wand: Success rate is not $100 \%$. Even when positive goal interdependence is implemented, and group members know that they should strive for a common purpose, social comparison is at work and occupies a great deal of the group members' attention (cf. Butera \& Darnon, 2017). Social comparison is a basic phenomenon that assesses one's competence in relation to that of similar others (Festinger, 1954; for 
a detailed discussion of social comparison theory see Utz, Chap. 14, this volume). Importantly for the present discussion, social comparison can be either inspiring or threatening for self-competence: It is inspiring when the partner may be considered as a source of help or information, or a model, and it is threatening when the partner may be considered as a source of humiliation or inferiority, or a competitor (Muller \& Fayant, 2010). It is important to note that social comparison can be either inspiring or threatening

\section{Box 8.4 Questions for Elaboration}

Teachers often call one of the pupils in front of the class to read a particularly well-written essay. In which circumstances will this pupil be inspiring? In which will the pupil be threatening?

whatever the direction of the comparison, be it upward (comparing with a superior partner) or downward (comparing with an inferior partner), as noted by Butera and Darnon (2017; see also Buunk, Collins, Taylor, VanYperen, \& Dakof, 1990). Even in a cooperative setting, inspiring and threatening comparisons may coexist, as demonstrated by Buchs, Butera, and Mugny (2004); Buchs, Pulfrey, Gabarrot, and Butera (2010); and more recently by Roseth, Lee, and Saltarelli
(2019). We will develop this work in a following section.

The question then arises of how to ensure that cooperative method, which is designed to promote positive interpersonal relationships, does not end up rendering partners threatening to each other. Buchs and Butera (2001) addressed this question by proposing that, besides positive goal interdependence, it is important to efficiently implement other positive interdependences in cooperative learning, in particular resource interdependence (see also Darnon, Buchs, \& Butera, 2002). They devised an experimental paradigm with, among others, two conditions: positive resource interdependence and resource independence. In all conditions two partners were given two texts they were asked to learn (and help their partner to learn), and were informed that a learning test would take place-on the two texts-at the end of the learning session, and again later in a delayed test (positive goal interdependence). Each partner was in charge of presenting one text, while the other facilitated the presentation with questions, one text at a time (positive role interdependence). In the positive resource interdependence condition, the two partners each received a different text; the two texts were complementary (they were both necessary for the learning test), but each student learned one text by reading it and the other by listening to the partner. In the resource independence condition, the two partners received

Table 8.1 Observed dynamics elicited by information distribution

\begin{tabular}{l|l|l}
\hline & $\begin{array}{l}\text { Identical information (resource } \\
\text { independence) }\end{array}$ & $\begin{array}{l}\text { Complementary information (positive } \\
\text { resource interdependence) }\end{array}$ \\
\hline $\begin{array}{l}\text { Relevance and utility of } \\
\text { relationship }\end{array}$ & Weak & Strong \\
\hline Climate & Individual/competitive & Cooperative \\
\hline Student involvement & Average & Strong \\
\hline Type of interactions & Discussion/confrontations & Summary/questions/explanations \\
\hline Individual accountability & Average & Strong \\
\hline Reciprocal interdependence & Weak & Strong \\
\hline Focus on social comparison of & Strong & Weak \\
\hline Partner's competence & Threatening and detrimental & Welcomed and beneficial \\
\hline Relevant mechanism & $\begin{array}{l}\text { Competence threat: competitive } \\
\text { relational activities as mediator }\end{array}$ & $\begin{array}{l}\text { Informational dependence: quality of } \\
\text { informational input as moderator }\end{array}$ \\
\hline
\end{tabular}

From Buchs and Butera (2004) 
both texts; the two partners then possessed identical information, and each student presented one of them to the partner, in turn. As noted by Buchs and Butera (2015), in positive resource interdependence, as compared to resource independence, "knowing that the other is dependent on oneself for accessing some information and that oneself is also dependent on the partner to access some other information would direct students to be more involved in information exchange" (p. 205). This is also supposed to elicit a series of other positive dynamics, summarized in Table 8.1.

\section{Inspiring and Threatening Partners}

The distinction between positive resource interdependence and resource independence is important and has been shown to influence not only partner perception and interpersonal relations, but also learning. In a study based on the general paradigm outlined earlier and conducted with university students, Buchs, Butera, and Mugny (2004), Study 2) measured the participants' perception of the partner's competence on two important aspects of their interaction, namely, perceived competence to understand information and perceived competence to summarize information. Learning outcomes were measured through a multiple-choice test with questions related to the texts students had to read and present. The questions required from the students a thorough comprehension of the study matter, not just recall or recognition, and the questionnaire was administered 1 month after the experimental sessions. Results revealed that when dyads worked with complementary texts (positive resource interdependence), perceived partner competence was positively related to a delayed measure of learning, as it should be in a genuine cooperative learning setting. In other words, the more competent the partner was perceived, the higher the learning outcomes score. Indeed, partners who are considered as more competent are more inspiring and more instrumental toward better learning. On the contrary, when dyads worked with identical texts (resource independence), perceived partner competence was negatively related to learning. In this case, a competent partner represented a threatening comparison target and reduced learning. Importantly, these results were replicated in a study conducted with primary school children (see Buchs \& Butera, 2015). In this work, actual performance of the partner was measured (number of correct pieces of information and explanations provided), instead of perceived partner competence, but the results of the two studies followed the same pattern as the results of Buchs and colleagues (2004).

Buchs and Butera (2009) also provided experimental evidence of this phenomenon in a study that manipulated the partner's competence. A confederate entered the laboratory with the participant and was assigned the role of summarizer for the first text, whereas the participant was to play the role of facilitator. The roles were reversed for the second text, but the measure of interest is the learning test for the first text. Indeed, the confederate had been instructed to deliver a summary that was either brilliant or average, depending on the condition. Even though the content was identical in all conditions, in the brilliant condition the confederate came with a very well-organized summary, with headings and well-defined technical terms. The confederate's notes started with an introduction, elaborated on all the important notions, and concluded on the most important information. In the average condition, the confederate came with quite a disorganized summary, often went back to a previous matter because of omissions, and used approximate terms. The results confirmed those of Buchs and colleagues (2004): When the dyad worked with complementary texts (positive resource interdependence), a brilliant partner induced better learning than an average partner, whereas when the dyad worked with identical texts (resource independence), a brilliant partner induced worse learning than an average partner. Thus, a competent partner, who should have represented an informational support in all conditions, appeared to promote learning outcomes only in the positive interdependence condition (for similar findings, see Neugebauer, Ray, \& Sassenberg, 2016). 


\section{Competence Threat}

In the studies by Buchs and colleagues (2004) and Buchs and Butera (2009), the interpretation of results is based on the idea that, notwithstanding the positive goal interdependence of a cooperative setting, a threatening social comparison may take place under resource independence, which would explain the detrimental effects that were found. A further study directly addressed the question of competence threat (Buchs et al., 2010). The main experiment in this article manipulated, as before, the way resources were distributed, as well as focus on social comparison, by allowing or not allowing students to take notes. The rationale for the latter manipulation was that notes allow direct comparison and confrontation of responses, which was confirmed by a pilot study. Results showed that a focus on social comparison did reduce learning, but in the resource independence condition and not in the positive resource interdependence condition. Moreover, and most importantly for the present contention, this effect was mediated by competence threat, namely, an aggregate measure that referred to the participants' concerns regarding the social comparison of competences with the partner. Thus, it appears that resource independence, as opposed to positive resource interdependence, leads partners to make sense of social comparison in terms of potential threat-a comparison that might be problematic for one's competence-which results in reduced learning.

These results are consistent with those of Ray, Neugebauer, Sassenberg, Buder, and Hesse (2013,

\section{Box 8.5 Question for Elaboration}

In professional settings, it often happens that employees are required to work in teams and are given a background training on the whole of the task at hand, which corresponds to possessing identical information. How can a supervisor prevent that the inevitable issues of relative status of team members interfere with the work to be completed?
Study 3), where participants who were not concerned by evaluative pressure (either positive or negative) achieved better learning outcomes when they were made aware of the possible positive resource interdependence with the partner (awareness of the partner's knowledge), than when they were not. To summarize, the results of Buchs et al. (2010) suggest that the benefits of cooperative learning require a carefully designed classroom setting to emerge: Distributing identical information to partners (resource independence) resulted in competence threat and reduced learning outcomes even in a cooperative setting with positive goal interdependence that should promote learning.

\section{The Promotion of Cooperative Methods}

According to Deutsch (1985), it is much easier to move from cooperation to competition than to revert from competition to cooperation. Indeed, in Western industrial countries, competition is pervasive, not only from an economic point of view but also when considering the dominant values of these countries. Accordingly, Schwartz (2007) has shown that self-enhancement values (wealth, power, achievement) are typical of countries with a capitalistic economy, especially those with more deregulated forms of capitalism (see also, Pulfrey \& Butera, 2013). Western industrialized countries are also more likely to display a population with independent selves, as compared to Eastern countries where people's selves tend to be more interdependent (Markus \& Kitayama, 1991). Moreover, the functioning of educational institutions, from school to university, is based on practices that induce competition among students (e.g., grading; cf. Black \& Wiliam, 1998; Pulfrey, Buchs, \& Butera, 2011), and students have learned that setting competitive achievement goals for themselves may be useful to succeed (e.g., Darnon, Dompnier, Delmas, Pulfrey, \& Butera, 2009; Dompnier, Darnon, Delmas, \& Butera, 2008).

In such a competitive environment, it is possible that implementing cooperative learning might seem at loggerheads with the values and practices of a given educational institution, 
Fig. 8.2 Learning outcomes as a function of work condition. (Adapted from Buchs et al., 2016). Note. The learning measure ranges from 0 to 6

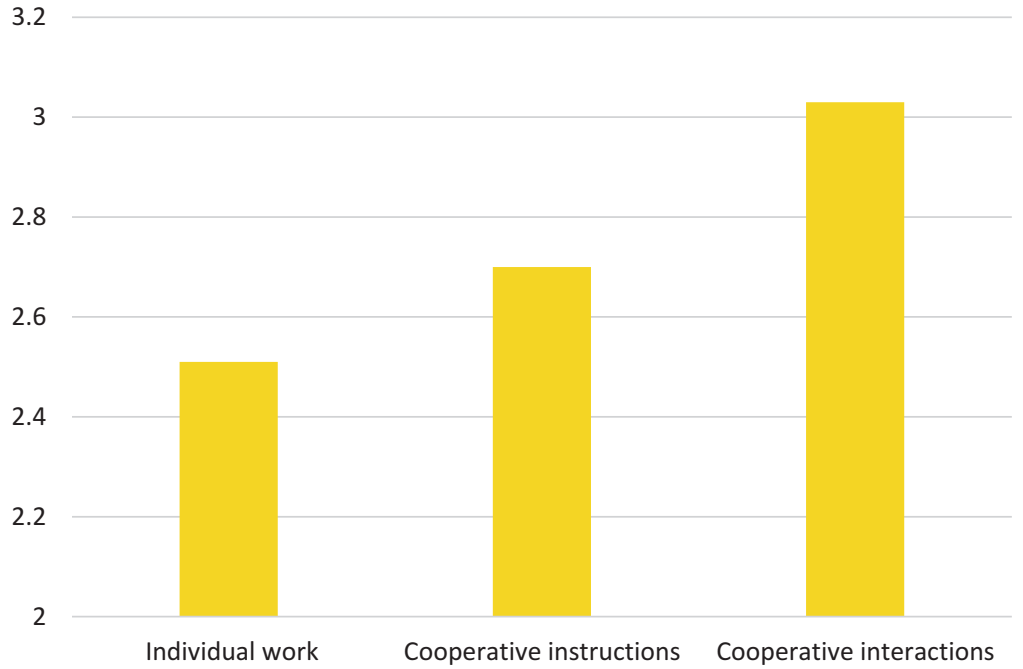

which might reduce acceptance of this method or lead to its failure. Thus, cooperative methods cannot be merely proposed or implemented; it must be promoted. In this respect, Buchs (2017) has highlighted an important distinction within the elements that constitute cooperative learning. She explained that elements such as positive interdependence or accountability are important because they structure the way cooperative learning is actually organized in groups, while some others such as social skills, group processing, and climate are important because they prepare the group members to interact cooperatively. In other words, a rigorous cooperative structure should be accompanied by some training, in order to allow students to move from an otherwise competitive environment to a cooperative setting (see also Webb, 2009).

With this in mind, Buchs, Gilles, Antonietti, and Butera (2016) devised an experimental intervention intended to promote cooperative learning in an area in which students experience great difficulties: statistics (Tomasetto, Matteucci, Carugati, \& Selleri, 2009). The intervention was carried out during a statistics course, where it was presented as a study on how students process information about statistics. During a 90-minute workshop, students reviewed the materials from the previous week (set theory), worked on two exercises related to the theory-allegedly as a training for the individual learning test - and finally sat the learning test, which was then used as the main dependent variable. The learning test included two types of questions: (a) a replication of the exercises completed in the previous steps of the study, but using new data (data not discussed during the statistics lecture); and (b) completely new exercises that required the generalization of the mathematical principles of set theory to a real-life situation.

The independent variable was manipulated during the exercise phase. The individual work condition (independence) was a control condition in which students worked alone on their study materials and exercises and was intended as a baseline that corresponds to the most common study strategy at university. The other two conditions involved working cooperatively in dyads. In both conditions, the experimental instructions introduced positive goal interdependence, individual responsibility/accountability, and encouragement of promotive interactions (Fig. 8.2). The cooperative instructions condition only included these instructions and corresponded to the basic structure implemented in cooperative learning. Finally, the cooperative interactions condition included the same three elements, but also introduced a "cooperative nudge," which consisted of two components. (1) The first component was introduced by a short text explaining the value of cooperation and the virtues of active listening and discussion. As 
Table 8.2 Cooperative skills introduced in the cooperative interactions condition

\begin{tabular}{|c|c|}
\hline How to translate cooperative skills into action & How to translate cooperative skills into words \\
\hline \multicolumn{2}{|l|}{ I explain how I process problems } \\
\hline $\begin{array}{l}\text { - I'm involved in the discussion. } \\
\text { - I try my best to be as clear as possible. }\end{array}$ & $\begin{array}{l}\text { - I explain the different steps ("I start by ..., then I ..."). } \\
\text { - I explain my rationale ("I do it because..."). } \\
\text { - I explain my strategies. } \\
\text { - I explain how I concretely do something. }\end{array}$ \\
\hline \multicolumn{2}{|c|}{ I check that I understand the way my partner processes problems } \\
\hline $\begin{array}{l}\text { I encourage my partner to develop his/her ideas. } \\
\text { - I let my partner explain without stopping him/her. } \\
\text { I listen to my partner's proposition even when I } \\
\text { don't agree. }\end{array}$ & $\begin{array}{l}\text { - I express my understanding ("All right, I understand"). } \\
\text { - I express my difficulties ("I do not understand; could } \\
\text { you please explain again?"). } \\
\text { - I reformulate what my partner says in order to be sure } \\
\text { I understand. } \\
\text { - I ask questions to invite my partner to be more explicit. } \\
\text { - I check for potential problems. }\end{array}$ \\
\hline \multicolumn{2}{|l|}{ I suggest alternative ways to process the problems } \\
\hline I'm involved in the discussion. & $\begin{array}{l}\text { - I suggest some alternatives ("and what if we started } \\
\text { by... I would rather do ...") } \\
\text { - I propose different alternatives. }\end{array}$ \\
\hline
\end{tabular}

From Buchs et al. (2016), reproduced with permission

mentioned earlier, cooperative values are not the default culture of university students in Western countries. (2) The second component was a series of recommendations inviting students to display three cooperative skills: "(a) explain how one processes problems, (b) be sure to understand the way the partner processes problems, and (c) suggest alternative ways to process problems" (Buchs et al., 2016, p. 965; Table 8.2). As mentioned earlier, active cooperation is not the default behavior among students.

The results revealed a linear trend in the pattern of learning outcomes across the three conditions, with the individual work condition scoring the lowest, followed by the cooperative instructions condition, and then by the cooperative interactions condition (Fig. 8.2). Interestingly, competence perception was also measured, through three items ("I realized that I had understood some things," "I felt I was able to master the work," and "I felt I was competent"). The results revealed that competence perception progressed in the same direction as learning outcomes, and that it mediated the effect of the experimental conditions on learning.

To conclude, this study shows that instructors may be well advised to prepare students to cooperate, before implementing cooperative learning, as cooperation is neither a value nor a common practice in education. This conclusion illustrates one of the main pitfalls in the use of cooperation in education, namely, the difference between structured and unstructured cooperation. The work on cooperative learning has long shown that "spontaneous" cooperation-simply relying on the encouragement to cooperate-does not hap-

\section{Summary}

- The nature of goal structure in groups affects group members' perceptions and behaviors, which in turn influence their learning outcomes.

- People interact cooperatively in groups when they perceive positive goal interdependence, or competitively when they perceive negative goal interdependence. With independent goals, they work individually.

- Cooperation requires positive goal interdependence, but also group members' responsibility and accountability, interactions directed toward the promotion of the partners, the use of social skills, and critical reflection upon group processes. 
- Cooperative methods favor learning outcomes, psychological as well as social adjustment, and positive relationships, as compared to competitive and individualistic methods.

- Cooperation is vulnerable to threatening social comparison: Interactions among group members that focus on relative status instead of the task may reduce the beneficial effects of cooperation.

- Cooperation is not socially and culturally valued in Western countries, and therefore cooperative learning requires training and promotion.

pen in most educational and work settings: Cooperative methods have been developed precisely to provide a structured environment that facilitates cooperative communication, information sharing, and relationships (e.g., Johnson \& Johnson, 1999; Tjosvold, 1984). The research reported in this section contributed to this endeavor by highlighting the importance of preparing students and workers to cooperate in order to counter, to some extent, the prevalently competitive routines they have acquired. The results presented here show that a brief intervention may be effective, but Buchs et al. (2016) also noted that the effect size they observed is rather small. This implies that longer or more frequent interventions may be needed.

\section{Recommended Reading}

Buchs, C., \& Butera, F. (2015). Cooperative learning and social skills development. In R. Gillies (Ed.), Collaborative learning: Developments in research and practice (pp. 201-217). New York, NY: Nova Science.

Butera, F., \& Darnon, C. (2017). Competence assessment, social comparison and conflict regulation. In A. Elliot, C. Dweck, \& D. Yaeger (Eds.), Handbook of competence and motivation (Theory and application) (2nd ed., pp. 192-213). New York, NY: Guilford Press.

Deutsch, M. (1949). A theory of cooperation and competition. Human Relations, 2, 129-152. https://doi.org/10.1177/001872674900200204

Johnson, D. W., \& Johnson, R. T. (2009). An educational psychology success story: Social interdependence theory and cooperative learning. Educational Researcher, 38, 365-379. https:// doi.org/10.3102/0013189X09339057

Topping, K. J., Buchs, C., Duran, D., \& Van Keer, H. (2017). Effective Peer Learning: From principles to practical implementation. London, UK \& New York, NY: Routledge.

\section{Guiding Answers to Questions in the Chapter}

1. Q (with Box 8.1): Imagine a cohesive and cooperative volleyball team. Give an example describing how substitutability, positive cathexis and inducibility intervene during a match.

A: During a smash from the other team, player X's effective dive to catch the ball reduces player Y's need to intervene (substitutability); this results in $\mathrm{Y}$ trusting $\mathrm{X}$ during the following action (positive cathexis) and avoiding to dive at the same time as $\mathrm{X}$ (inducibility).

2. Q (with Fig. 8.1): Why are responsibility and accountability important to cooperation? What do they add to positive goal interdependence?

A: Because, even in a group that pursues a common goal, some members may be tempted to free ride and benefit from the group's work without investing some effort.

3. Q (with Box 8.3): Could cooperative learning be used to integrate migrant children in the host country's regular classes?

A: Cooperative learning has been shown to be helpful in improving the learning and interper- 
sonal relations in groups with ethnic diversity, and in groups with differences in ability.

4. Q (with Box 8.4): Teachers often call one of the pupils in front of the class to read a particularly well written essay. In which circumstances will this pupil be inspiring? Which will be threatening?

A: If this pupil is a possible companion (e.g., a future partner for an assignment), s/he will be perceived as a source of inspiration. If the pupil is a possible rival (e.g., the teacher's pet), s/he will be perceived as a source of threat.

5. Q (with Box 8.5): In professional settings, it often happens that employees are required to work in teams and are given a background training on the whole of the task at hand, which corresponds to possessing identical information. How can a supervisor prevent that the inevitable issues of relative status of team members interfere with the work to be completed?

A: Divide the task and the resources in complementary chunks and distribute them to different employees with complementary roles.

\section{References}

Abrami, P. C. (1995). Classroom connections: Understanding and using cooperative learning. Harcourt College Pub: Fort Worth, Texas.

Aronson, E., \& Patnoe, S. (1997). The jigsaw classroom: Building cooperation in the classroom (2nd ed.). New York, NY: Addison Wesley Longman.

Bennett, B., Rolheiser, C., \& Stevahn, L. (1991). Cooperative learning: Where hearts meets mind. Ontario, Canada: Educational Connections.

Black, P., \& Wiliam, D. (1998). Inside the black box: Raising standards through classroom assessment. London, UK: Granada Learning.

Buchs, C. (2017). Apprendre ensemble: des pistes pour structurer les interactions en classe (Learning together: Recommendations for structuring classroom interaction). In M. Giglio \& F. Arcidiacono (Eds.), Les interactions sociales en classe: réflexions et perspectives (p. 2017). Berne, Switzerland: Peter Lang.

Buchs, C., \& Butera, F. (2001). Complementarity of information and quality of relationship in cooperative learning. Social Psychology of Education, 4, 335-357. https://doi.org/10.1023/A:1011392906032

Buchs, C., \& Butera, F. (2004). Socio-cognitive conflict and the role of student interaction in learning. New Review of Social Psychology, 3, 80-87.

Buchs, C., \& Butera, F. (2009). Is a partner's competence threatening during dyadic cooperative work? It depends on resource interdependence. European Journal of Psychology of Education, 24, 145-154. https://doi.org/10.1007/BF03173007

Buchs, C., \& Butera, F. (2015). Cooperative learning and social skills development. In R. Gillies (Ed.), Collaborative learning: Developments in research and practice (pp. 201-217). New York, NY: Nova Science.

Buchs, C., Butera, F., \& Mugny, G. (2004). Resource in(ter)dependence, student interactions and performance in cooperative learning. Educational Psychology, 24, 291-314. https://doi. org/10.1080/0144341042000211661

Buchs, C., Butera, F., Mugny, G., \& Darnon, C. (2004). Conflict resolution and cognitive outcomes. Theory Into Practice, 43, 23-30. https://doi.org/10.1207/ s15430421tip4301_4

Buchs, C., Gilles, I., Antonietti, J. P., \& Butera, F. (2016). Why students need to be prepared to cooperate: A cooperative nudge in statistics learning at university. Educational Psychology, 36, 956-974. https://doi.org/ 10.1080/01443410.2015.1075963

Buchs, C., Margas, N., Cazin, C., Ramirez, M., \& Fratianni, S. (2018). Des activités plurilingues dans une perspective coopérative pour favoriser l'équité dans les classes caractérisée par une forte diversité linguistique (Multi-lingual activities in a cooperative perspective promote equality in classes with a high linguistic diversity). Education et francophonie, 46(2), 249-269.

Buchs, C., Pulfrey, C., Gabarrot, F., \& Butera, F. (2010). Competitive conflict regulation and informational dependence in peer learning. European Journal of Social Psychology, 40, 418-435. https://doi. org/10.1002/ejsp.631

Butera, F., \& Buchs, C. (2005). Reasoning together: From focussing to decentring. In V. Girotto \& P. N. JohnsonLaird (Eds.), The shape of reason (pp. 193-203). Hove, UK: Psychology Press.

Butera, F., \& Darnon, C. (2017). Competence assessment, social comparison and conflict regulation. In A. Elliot, C. Dweck, \& D. Yaeger (Eds.), Handbook of competence and motivation (Theory and application) (2nd ed., pp. 192-213). New York, NY: Guilford Press.

Butera, F., \& Mugny, G. (1995). Conflict between incompetences and influence of a low-competence source in hypothesis testing. European Journal of Social Psychology, 25, 457-462. https://doi.org/10.1002/ ejsp. 2420250408

Butera, F., \& Mugny, G. (2001). Conflicts and social influences in hypothesis testing. In C. De Dreu \& N. De Vries (Eds.), Group consensus and minority influence: 
Implications for innovation (pp. 160-182). Oxford, UK: Blackwell.

Buunk, B. P., Collins, R. L., Taylor, S. E., VanYperen, N. W., \& Dakof, G. A. (1990). The affective consequences of social comparison: Either direction has its ups and downs. Journal of Personality and Social Psychology, 59, 1238-1249. https://doi. org/10.1037/0022-3514.59.6.1238

Darnon, C., Buchs, C., \& Butera, F. (2002). Epistemic and relational conflict in sharing information during cooperative learning. Swiss Journal of Psychology, 61, 139151. https://doi.org/10.1024//1421-0185.61.3.139

Darnon, C., Dompnier, B., Delmas, F., Pulfrey, C., \& Butera, F. (2009). Achievement goal promotion at university: Social desirability and social utility of mastery and performance goals. Journal of Personality and Social Psychology, 96, 119-134. https://doi. org/10.1037/a0012824

De Cremer, D., \& Van Lange, P. A. (2001). Why prosocials exhibit greater cooperation than proselfs: The roles of social responsibility and reciprocity. European Journal of Personality, 15, 5-18. https://doi. org/10.1002/per.418

De Dreu, C. K., Nijstad, B. A., \& van Knippenberg, D. (2008). Motivated information processing in group judgment and decision making. Personality and Social Psychology Review, 12, 22-49. https://doi. org/10.1177/1088868307304092

Deutsch, M. (1949). A theory of cooperation and competition. Human Relations, 2, 129-152. https://doi. org/10.1177/001872674900200204

Deutsch, M. (1962). Cooperation and trust: Some theoretical notes. In M. R. Jones (Ed.), Nebraska symposium on motivation (pp. 275-319). Lincoln: University of Nebraska Press.

Deutsch, M. (1985). Distributive justice: A social psychological perspective. New Haven, CT: Yale University Press.

Dompnier, B., Darnon, C., Delmas, F., \& Butera, F. (2008). Achievement goals and social judgment: The performance-approach paradox. International Review of Social Psychology, 21, 247-271.

Dyson, B. (2001). Cooperative learning in an elementary physical education program. Journal of Teaching in Physical Education, 20, 264-281. https://doi. org/10.1123/jtpe.20.3.264

Elliot, A. J., Jury, M., \& Murayama, K. (2018). Trait and perceived environmental competitiveness in achievement situations. Journal of Personality, 86, 353-367. https://doi.org/10.1111/jopy.12320

Esser, J. K. (1998). Alive and well after 25 years: A review of groupthink research. Organizational Behavior and Human Decision Processes, 73, 116-141. https://doi. org/10.1006/obhd.1998.2758

Festinger, L. (1954). A theory of social comparison processes. Human Relations, 7, 117-140. https://doi. org/10.1177/001872675400700202

Hattie, J. (2008). Visible learning: A synthesis of over 800 meta-analyses relating to achieve- ment. New York, NY: Routledge. https://doi. org/10.1080/01443410903415150

Hwong, N., Caswell, A., Johnson, D. W., \& Johnson, R. (1993). Effects of cooperative and individualistic learning on prospective elementary teachers' music achievement and attitudes. Journal of Social Psychology, 133, 53-64. https://doi.org/10.1080/0022 4545.1993.9712118

Janis, I. L. (1972). Victims of groupthink. Boston, MA: Houghton Mifflin.

Johnson, D. W. (2009). Reaching out: Interpersonal effectiveness and self-actualization (10th ed.). Boston, MA: Allyn \& Bacon.

Johnson, D. W. (2015). Constructive controversy: Theory, research, practice. New York, NY: Cambridge University Press. https://doi.org/10.1017/ CBO9781316105818

Johnson, D. W., \& Johnson, F. (2006). Joining together: Group theory and group skills (9th ed.). Boston, MA: Allyn \& Bacon.

Johnson, D. W., \& Johnson, R. T. (1974). Instructional goal structure: Cooperative, competitive, or individualistic. Review of Educational Research, 44, 213-240. https://doi.org/10.3102/00346543044002213

Johnson, D. W., \& Johnson, R. T. (1989). Cooperation and competition: Theory and research. Edina, MN: Interaction Book Co.

Johnson, D. W., \& Johnson, R. T. (1999). Making cooperative learning work. Theory Into Practice, 38, 67-73. https://doi.org/10.1080/00405849909543834

Johnson, D. W., \& Johnson, R. T. (2002). Social interdependence theory and university instruction: Theory into practice. Swiss Journal of Psychology, 61, 119-129. https://doi.org/10.1024//1421-0185.61.3.119

Johnson, D. W., \& Johnson, R. T. (2005). New developments in social interdependence theory. Genetic, Social, and General Psychology Monographs, 131, 285-358. https://doi.org/10.3200/MONO.131.4.285-358

Johnson, D. W., \& Johnson, R. T. (2007). Creative controversy: Intellectual challenge in the classroom (4th ed.). Edina, MN: Interaction Book Company.

Johnson, D. W., \& Johnson, R. T. (2009). An educational psychology success story: Social interdependence theory and cooperative learning. Educational Researcher, 38, 365-379. https://doi.org/10.3102/001 3189X09339057

Johnson, D. W., \& Johnson, R. T. (2015). Theoretical approaches to cooperative learning. In R. M. Gillies (Ed.), Collaborative learning: Developments in research and practice (pp. 17-46). New York, NY: Nova Science.

Johnson, D. W., Johnson, R. T., \& Holubec, E. (1998). Cooperation in the classroom (6th ed.). Edina, MN: Interaction Book Company.

Johnson, D. W., Johnson, R. T., \& Holubec, E. J. (1993). Circles of learning: Cooperation in the classroom. Edina, MN: Interaction Book Company.

Johnson, D. W., Johnson, R. T., \& Maruyama, G. (1983). Interdependence and interpersonal attraction among 
heterogeneous and homogeneous individuals: A theoretical formulation and a meta-analysis of the research. Review of Educational Research, 5, 5-54. https://doi. org/10.3102/00346543053001005

Johnson, D. W., Johnson, R. T., \& Stanne, M. B. (2000). Cooperative learning methods: A meta-analysis. Retrieved from http://www.co-operation.org/pages/ cl-methods.html

Karau, S., \& Williams, K. (1993). Social loafing: A metaanalytic review and theoretical integration. Journal of Personality and Social Psychology, 65, 681-706. https://doi.org/10.1037/0022-3514.65.4.681

Kaufman, N. H. (1994). A survey of law school grading practices. Journal of Legal Education, 44, 415-423.

Latané, B., Williams, K., \& Harkins, S. (1979). Many hands make light the work: The causes and consequences of social loafing. Journal of Personality and Social Psychology, 37, 822-832. https://doi. org/10.1037/0022-3514.37.6.822

Lew, M., Mesch, D., Johnson, D. W., \& Johnson, R. (1986). Positive interdependence, academic and collaborativeskills group contingencies and isolated students. American Educational Research Journal, 23, 476-488. https://doi.org/10.3102/00028312023003476

Markus, H. R., \& Kitayama, S. (1991). Culture and the self: Implications for cognition, emotion, and motivation. Psychological Review, 98, 224-253. https://doi. org/10.1037/0033-295X.98.2.224

Moreland, R. L., \& Levine, J. M. (1992). The composition of small groups. In E. J. Lawler, B. Markovsky, C. Ridgeway, \& H. A. Walker (Eds.), Advances in group processes (Vol. 9, pp. 237-280). Greenwich, CT: JAI Press.

Muller, D., \& Fayant, M. P. (2010). On being exposed to superior others: Consequences of self-threatening upward social comparisons. Social and Personality Psychology Compass, 4, 621-634. https://doi. org/10.1111/j.1751-9004.2010.00279.x

Muller Mirza, N., \& Perret-Clermont, A.-N. (Eds.). (2009). Argumentation and education. Theoretical foundations and practices. New York, NY: Springer. https://doi.org/10.1007/s10503-009-9176-5

Neugebauer, J., Ray, D., \& Sassenberg, K. (2016). When being worse helps: The influence of upward social comparisons and knowledge awareness on learner engagement and learning in peer-to-peer knowledge exchange. Learning \& Instruction, 44, 41-52. https:// doi.org/10.1016/j.learninstruc.2016.02.007

Pulfrey, C., Buchs, C., \& Butera, F. (2011). Why grades engender performance avoidance goals: The mediating role of autonomous motivation. Journal of Educational Psychology, 103, 683-700. https://doi. org/10.1037/a0023911

Pulfrey, C., \& Butera, F. (2013). Why neo-liberal values of self-enhancement lead to cheating in higher education: A motivational account. Psychological Science, 24, 21532162. https://doi.org/10.1177/0956797613487221

Quiamzade, A., \& Mugny, G. (2009). Social influence and threat in confrontations between competent peers.
Journal of Personality and Social Psychology, 97, 652-666. https://doi.org/10.1037/a0015822

Ray, D., Neugebauer, J., Sassenberg, K., Buder, J., \& Hesse, F. W. (2013). Motivated shortcomings in explanation: The role of comparative self-evaluation and awareness of explanation recipient knowledge. Journal of Experimental Psychology: General, 142, 445-457. https://doi.org/10.1037/a0029339

Roseth, C. J., Johnson, D. W., \& Johnson, R. T. (2008). Promoting early adolescents' achievement and peer relationships: The effects of cooperative, competitive, and individualistic goal structures. Psychological Bulletin, 134, 223-246. https://doi. org/10.1037/0033-2909.134.2.223

Roseth, C. J., Lee, Y. K., \& Saltarelli, W. A. (2019). Reconsidering jigsaw social psychology: Longitudinal effects on social interdependence, sociocognitive conflict regulation, motivation, and achievement. Journal of Educational Psychology, 111(1), 149-169

Ryan, R. M., \& Deci, E. L. (2000). Self-determination theory and the facilitation of intrinsic motivation, social development, and well-being. American Psychologist, 55, 68-78. https://doi. org/10.1037/0003-066X.55.1.68

Schwartz, S. H. (2007). Cultural and individual value correlates of capitalism: A comparative analysis. Psychological Inquiry, 18, 52-57. https://doi. org/10.1080/10478400701388963

Schwartz, S. H., Cieciuch, J., Vecchione, M., Davidov, E., Fischer, R., Beierlein, C., ... Dirilen-Gumus, O. (2012). Refining the theory of basic individual values. Journal of Personality and Social Psychology, 103, 663-688. https://doi.org/10.1037/a0029393

Sharan, Y. (2010). Cooperative learning: A diversified pedagogy for diverse classrooms. Intercultural Education, 21(3), 195-203. https://doi. org/10.1080/14675981003760390

Sherif, M. (1958). Superordinate goals in the reduction of intergroup conflict. American Journal of Sociology, 63, 349-356. https://doi.org/10.1086/222258

Sherif, M. (1966). In common predicament: Social psychology of intergroup conflict and cooperation. Boston: Houghton Mifflin comp.

Slavin, R. E. (1983). When does cooperative learning increase student achievement? Psychological Bulletin, 94, 429. https://doi.org/10.1037/0033-2909.94.3.429

Slavin, R. E. (2011). Instruction based on cooperative learning. In R. Mayer (Ed.), Handbook of research on learning and instruction (pp. 344-360). London, UK: Taylor and Francis.

Slavin, R. E. (2015). Cooperative learning in elementary schools. Education 3-13: International Journal of Primary, Elementary and Early Years Education, 43, 5-14. https://doi.org/10.1080/03004279.2015.96 3370

Smith, K., Johnson, D. W., \& Johnson, R. T. (1981). Can conflict be constructive? Controversy versus concurrence seeking in learning groups. Journal of Educational Psychology, 73, 651. https://doi. org/10.1037/0022-0663.73.5.651 
Sommet, N., Pulfrey, C., \& Butera, F. (2013). Did my MD really go to university to learn? Detrimental effects of numerus clausus on self-efficacy, mastery goals and learning. PLoS One, 8(12), e84178. https://doi. org/10.1371/journal.pone.0084178

Tjosvold, D. (1984). Cooperation theory and organizations. Human Relations, 37, 743-767. https://doi. org/10.1177/001872678403700903

Tjosvold, D., \& Tjosvold, M. (2015). Building the team organization: How to open minds, resolve conflict, and ensure cooperation. New York, NY: Palgrave Macmillan. https://doi.org/10.1057/9781137479938

Toma, C., \& Butera, F. (2009). Hidden profiles and concealed information: Strategic information sharing and use in group decision making. Personality and Social Psychology Bulletin, 35, 793-806. https://doi. org/10.1177/0146167209333176

Tomasetto, C., Matteucci, M. C., Carugati, F., \& Selleri, P. (2009). Effect of task presentation on students' performances in introductory statistics courses. Social Psychology of Education, 12, 191-211. https:// doi.org/10.1007/s11218-008-9081-z
Topping, K. J., Buchs, C., Duran, D., \& Van Keer, H. (2017). Effective peer learning: From principles to practical implementation. London, UK \& New York, NY: Routledge.

Triandis, H. C. (1993). Collectivism and individualism as cultural syndromes. Cross-Cultural Research, 27, 155180. https://doi.org/10.1177/106939719302700301

Webb, N. M. (2009). The teacher's role in promoting collaborative dialogue in the classroom. British Journal of Educational Psychology, 79, 1-28. https://doi.org/1 0.1348/000709908X380772

Wegerif, R., Mercer, N., \& Dawes, L. (1999). From social interaction to individual reasoning: An empirical investigation of a possible sociocultural model and cognitive development. Learning and Instruction, 9, 493-516. https://doi.org/10.1016/ S0959-4752(99)00013-4

Yager, S., Johnson, R. T., Johnson, D. W., \& Snider, B. (1986). The impact of group processing on achievement in cooperative learning groups. The Journal of Social Psychology, 126, 389-397. https://doi.org/10.1 080/00224545.1986.9713601 